OPEN ACCESS

Edited by:

Rong Li,

Peking University Third Hospital, China

Reviewed by:

Katja Hummitzsch,

University of Adelaide, Australia Luigi Carbone,

University of Naples Federico II, Italy

*Correspondence: Yichun Guan guanyichun1616@126.com

${ }^{\dagger}$ These authors have contributed equally to this work and share first authorship

Specialty section: This article was submitted to Reproduction, a section of the journal

Frontiers in Endocrinology

Received: 01 October 2021 Accepted: 23 November 2021 Published: 08 December 2021

Citation:

Du M, Zhang J, Yu X and Guan Y (2021) Elevated Anti-Müllerian Hormone Is an Independent Risk Factor for Preterm Birth Among Patients With Overweight

Polycystic Ovary Syndrome.

Front. Endocrinol. 12:788000. doi: 10.3389/fendo.2021.788000

\section{Elevated Anti-Müllerian Hormone Is an Independent Risk Factor for Preterm Birth Among Patients With Overweight Polycystic Ovary Syndrome}

\author{
Mingze $\mathrm{Du}^{\dagger}$, Junwei Zhang ${ }^{\dagger}$, Xiaona Yu and Yichun Guan * \\ The Reproductive Center, The Third Affiliated Hospital of Zhengzhou University, Zhengzhou, China
}

Objective: To explore whether elevated anti-Müllerian hormone (AMH) levels affect the rate of preterm birth (PTB) among PCOS patients with different BMls.

Methods: In this retrospective cohort study, patients with PCOS who had undergone IVF/ ICSI from January 2017 to December 2019 were included for potential evaluation. A total of 2368 singleton live births from PCOS patients were included. According to the BMI, all the PCOS patients were divided into two groups: $\mathrm{BMl}<24 \mathrm{~kg} / \mathrm{m}^{2}$ and $\mathrm{BMl} \geq 24 \mathrm{~kg} / \mathrm{m}^{2}$. In total, 1339 PCOS patients with a BMl $<24 \mathrm{~kg} / \mathrm{m}^{2}$ were grouped according to their serum AMH levels: (1) $<2.71 \mathrm{ng} / \mathrm{ml}$ ( $\mathrm{n}=333$ ), (2) $2.71-4.08 \mathrm{ng} / \mathrm{ml}$ ( $\mathrm{n}=330$ ), (3) $4.09-6.45 \mathrm{ng} / \mathrm{ml}$ $(\mathrm{n}=351)$, and (4) $>6.45 \mathrm{ng} / \mathrm{ml}(\mathrm{n}=325)$. Additionally, 1029 cycles of patients with a $\mathrm{BMl} \geq 24$ $\mathrm{kg} / \mathrm{m}^{2}$ were grouped according to the serum AMH level: (1) $<2.71 \mathrm{ng} / \mathrm{ml}(\mathrm{n}=255)$, (2) 2.71 $4.08 \mathrm{ng} / \mathrm{ml}(\mathrm{n}=267)$, (3) 4.09-6.45 ng/ml ( $\mathrm{n}=239)$, and (4) $>6.45 \mathrm{ng} / \mathrm{ml}(\mathrm{n}=268)$, with $<2.71$ $\mathrm{ng} / \mathrm{ml}$ being considered the reference group. The grouping was based mainly on the interquartile range of serum AMH levels. The primary outcome of the study was PTB. The secondary outcomes were low birth weight (LBW), small for gestational age (SGA), macrosomia and large for gestational age (LGA).

Results: Regarding PCOS patients with a BMl<24 kg/m², compared with the PTB rate of the $\mathrm{AMH}<2.71 \mathrm{ng} / \mathrm{ml}$ group, the PTB rates of the different groups were not significantly different (AMH 2.71-4.08, AOR (95\% Cl)=1.01 (0.52-2.00), $\mathrm{P}=0.99 ; \mathrm{AMH} 4.09-6.45, \mathrm{AOR}$ $(95 \% \mathrm{Cl})=0.93(0.45-1.91), \mathrm{P}=0.85 ; \mathrm{AMH}>6.45, \mathrm{AOR}(95 \% \mathrm{Cl})=0.78 \quad(0.35-1.73)$, $\mathrm{P}=0.54)$. Regarding PCOS patients with a $\mathrm{BMl} \geq 24 \mathrm{~kg} / \mathrm{m}^{2}$, compared with the PTB rate of the $\mathrm{AMH}<2.71 \mathrm{ng} / \mathrm{ml}$ group, the PTB rate of the $\mathrm{AMH}>6.45 \mathrm{ng} / \mathrm{ml}$ group was significantly higher $(\mathrm{OR}=2.47 ; 95 \% \mathrm{Cl}=1.34-4.55)$. After multiple logistic regression analysis, the risk of $\mathrm{PTB}$ in the $\mathrm{AMH}>6.45 \mathrm{ng} / \mathrm{ml}$ group was 2.1 times that in the $\mathrm{AMH}<2.71 \mathrm{ng} / \mathrm{ml}$ group $(\mathrm{AOR}=2.1,95 \% \mathrm{Cl}=1.01-4.37, \mathrm{P}=0.04)$. However, no statistically significant difference was found in the rate of SGA, LBW, macrosomia or LGA among patients in the different serum $\mathrm{AMH}$ groups. 


\section{Conclusion: For PCOS patients, a BMl $\geq 24 \mathrm{~kg} / \mathrm{m}^{2}$ plus serum $\mathrm{AMH}>6.45 \mathrm{ng} / \mathrm{ml}$ (75th percentile) is an independent risk factor for PTB.}

Keywords: anti-Müllerian hormone, polycystic ovary syndrome, preterm birth, in vitro fertilization, body mass index

\section{INTRODUCTION}

Polycystic ovary syndrome (PCOS) is characterized by ovarian dysfunction and other cardinal features-namely, hyperandrogenism and polycystic ovary (PCO) morphology. Additionally, menstrual irregularities, signs of androgen excess, obesity and infertility are common clinical manifestations (1). The clinical features of PCOS patients are heterogeneous, and the most commonly used diagnostic criteria are the Rotterdam criteria, established in 2003 (1). PCOS occurs primarily in women of reproductive age. The prevalence of PCOS has been reported to range from $8 \%$ to $13 \%$ worldwide (2-4), and the prevalence of PCOS among Chinese women aged 19-45 years is close to $5.6 \%$ (5). The rapid development of assisted reproductive technology (ART) made this method crucial for the treatment of infertility, and it is widely used in the PCOS population compared with the non-PCOS population (6). The safety of ART for the offspring of the PCOS population has been a focus of research. Current studies have reported that PCOS patients have increased rates of pregnancy complications, including pregnancy-induced hypertension and gestational diabetes mellitus, and an increased miscarriage rate (7). Studies have also indicated that the preterm birth (PTB) rate of PCOS patients is increased, regardless of whether pregnancy is achieved spontaneously or through IVF (8-10).

Anti-Müllerian hormone (AMH) is a dimeric glycoprotein and a transforming growth factor-beta superfamily member that acts on tissue growth and differentiation (11). AMH is produced by granulosa cells from preantral and antral follicles, and its expression is restricted in growing follicles until they have reached the size and differentiation state at which they are selected for dominance via pituitary FSH (12). The AMH level basically reflects the follicular reserve in the ovary.

Compared with women without PCOS, those with PCOS have more antral follicles $(13,14)$. Thus, the circulating AMH levels in women with PCOS are two to three times higher than those in healthy controls $(13,15)$, a finding that may be related not only to excessive accumulation of antral follicles but also to increased granulosa cell AMH secretion (16-18). Therefore, the serum AMH level may be related to the severity of PCOS, and whether a high AMH level influences offspring remains uncertain. To our best knowledge, only 2 clinical studies have analyzed the relationship between elevated AMH levels and premature delivery of offspring after IVF $(9,10)$. However, the data are limited, and current studies do not distinguish the effects of different body mass indices (BMIs). Even so, the BMI is related to PCOS severity and offspring outcomes (19-21). Therefore, the impact of AMH levels on the offspring of PCOS patients in different BMI groups must be further analyzed. This study aimed to evaluate whether elevated AMH levels affect the rate of preterm birth (PTB) among PCOS patients with different BMIs.

\section{MATERIALS AND METHODS}

\section{Study Design and Population}

This was a single-center retrospective cohort study approved by the Ethics Committee of the Third Affiliated Hospital of Zhengzhou University. Patients with PCOS who had undergone in vitro fertilization (IVF)/intracytoplasmic sperm injection (ICSI) at the Reproductive Center of the Third Affiliated Hospital of Zhengzhou University from January 2017 to December 2019 were included for potential evaluation in this study. The diagnosis of PCOS was based on the Rotterdam criteria established in the 2003 Rotterdam consensus workshop, which required that at least two of the following three criteria were met: oligomenorrhea and/or anovulation, clinical and/or biochemical signs of hyperandrogenism, and polycystic ovaries on ultrasound scanning (1). Only cycles with fresh embryo transfer and singleton delivery were included. Cycles with pregnancy-induced hypertension, gestational diabetes mellitus, adenomyosis, uterine malformations, endometrial polyps and preimplantation genetic testing (PGT) were excluded. The baseline and cycle information of all the patients was obtained from our electronic medical record system, and the information on newborns was obtained from the followup records of professional nurses.

According to the BMI, PCOS patients were divided into two groups: $B M I<24 \mathrm{~kg} / \mathrm{m}^{2}$ and $\mathrm{BMI} \geq 24 \mathrm{~kg} / \mathrm{m}^{2}$. Next, we divided the cycles into four groups based on the AMH levels: (1) $<2.71 \mathrm{ng} / \mathrm{ml}$, (2) $2.71-4.08 \mathrm{ng} / \mathrm{ml}$, (3) $4.09-6.45 \mathrm{ng} / \mathrm{ml}$, and (4) $>6.45 \mathrm{ng} / \mathrm{ml}$. The $<2.71 \mathrm{ng} / \mathrm{ml}$ group was considered the reference group, and grouping was based primarily on the interquartile range of the serum AMH levels.

\section{Clinical Protocols}

The mothers were subjected to our center's conventional ovulation stimulation protocols-namely, gonadotrophinreleasing hormone $(\mathrm{GnRH})$ agonist protocols or flexible $\mathrm{GnRH}$ antagonist protocols. The specific ovulation protocol details have been described in our previous studies $(22,23)$. For both protocols, the dose of follicle-stimulating hormone $(\mathrm{rFSH})$ was adjusted according to the follicle response, as determined by transvaginal ultrasound monitoring and blood hormone level measurements. When the diameter of the dominant follicle was greater than $20 \mathrm{~mm}$ or when at least three follicles reached $18 \mathrm{~mm}$ in diameter, ovulation induction was triggered with 5000 to 10000 IU human chorionic gonadotrophin (hCG; Lizhu Pharmaceutical Trading, China). Oocyte retrieval was performed 36 hours later. 
Routine IVF or ICSI was performed according to the man's semen quality. Women underwent the transfer of 1 to 2 cleavage-stage embryos on the third day or transfer of a single fresh blastocyst on the fifth day after fertilization. Routine corpus luteum support-namely, oral dydrogesterone (10 mg twice daily) (Abbott Co. America) - was initially provided on the day of oocyte retrieval, and intravaginal administration of $90 \mathrm{mg}$ of a progesterone sustained-release vaginal gel (Merck Co. Germany) was performed. Corpus luteum support was performed until at least 55 days after transplantation if pregnancy occurred. The serum hormone levels were tested using the Cobas C8000 system (Roche Diagnostics, Germany), and the measurement approaches were described in our previous study (22).

\section{Outcome Measures and Definition}

PTB was the main outcome for this analysis and was defined as a birth occurring after 28 weeks and before 37 completed weeks of gestation. The secondary outcome measures were a low birth weight (LBW, defined as a neonatal birth weight less than 2500 g), small for gestational age [SGA, defined as a birth weight less than the 10th percentile for gestational age, per the weight criteria for Chinese newborns (24)], macrosomia (defined as a neonatal birth weight greater than $4000 \mathrm{~g}$ ) and large for gestational age [LGA, defined as a birth weight larger than the 90th percentile for the sex-specific birth weight, per the sexspecific birth weight criteria for weight among Chinese newborns (24)].

\section{Statistical Analysis}

All statistical management and analyses were performed using SPSS software, version 22.0.

The one-sample Kolmogorov-Smirnov test was used to check for the normality of continuous variables. Continuous variables with abnormal distributions were expressed as the median (P25, P75), and the between-group differences were assessed using the Wilcoxon rank-sum test. Categorical variables were represented as the number of cases (n) and percentage (\%). The means from chi-squared analyses were used to assess the differences between groups using Fisher's exact test when necessary. For the outcome measures-namely, PTB, LBW, SGA, macrosomia and LGA-multiple logistic regression was used to adjust for the baseline characteristics. Odds ratios (ORs) and adjusted odds ratios (AORs) with 95\% confidence intervals (CIs) were calculated. $\mathrm{P}<0.05$ was considered to be statistically significant.

\section{RESULTS}

\section{Study Population}

In this study, 2368 singleton live births from PCOS patients were included in the analysis from January 2017 to December 2019.

In total, 1339 PCOS patients with a $\mathrm{BMI}<24 \mathrm{~kg} / \mathrm{m}^{2}$ were grouped according to the serum AMH level: (1) $<2.71 \mathrm{ng} / \mathrm{ml}$ ( $\mathrm{n}=333)$, (2) 2.71-4.08 ng/ml ( $\mathrm{n}=330)$, (3) 4.09-6.45 ng/ml ( $\mathrm{n}=351)$, and (4) $>6.45 \mathrm{ng} / \mathrm{ml}(\mathrm{n}=325)$.
A total of 1029 cycles were evaluated from patients with a $\mathrm{BMI} \geq 24 \mathrm{~kg} / \mathrm{m}^{2}$, and they were grouped according to the serum AMH level: (1) <2.71 ng/ml ( $\mathrm{n}=255)$, (2) 2.71-4.08 ng/ml ( $\mathrm{n}=267)$, (3) 4.09-6.45 ng/ml $(\mathrm{n}=239)$, and (4) $>6.45 \mathrm{ng} / \mathrm{ml}(\mathrm{n}=268)$.

\section{Baseline and Cycle Characteristics}

Detailed information on the baseline and cycle characteristics between groups is presented in Table 1. Significant differences were found in the maternal age $(\mathrm{P}<0.001)$, paternal age $(\mathrm{P}<0.001)$, duration of infertility $(\mathrm{P}<0.001)$, type of infertility $(\mathrm{P}<0.001)$, basal serum FSH level $(\mathrm{P}<0.001)$, basal antral follicle count $(\mathrm{P}<0.001)$, dosage of gonadotropin $(\mathrm{P}<0.001)$, duration of ovarian stimulation $(\mathrm{P}<0.001)$, number of oocytes retrieved $(\mathrm{P}=0.01)$, endometrial thickness on the trigger day $(\mathrm{P}=0.01)$ and fertilization method $(\mathrm{P}=0.045)$ between the $\mathrm{BMI}<24 \mathrm{~kg} / \mathrm{m}^{2}$ group and $\mathrm{BMI} \geq 24 \mathrm{~kg} / \mathrm{m}^{2}$ group. The neonatal birth weight was higher in the $\mathrm{BMI} \geq 24 \mathrm{~kg} / \mathrm{m}^{2}$ group than in the $\mathrm{BMI}<24 \mathrm{~kg} / \mathrm{m}^{2}$ group (3500.0 (3150.0, 3800.0) vs. 3300.0 (3050.0, 3600.0); $\mathrm{P}<0.001)$. Differences were found in the gestational week at delivery between the groups $(\mathrm{P}=0.01)$. The serum $\mathrm{AMH}$ level $(\mathrm{P}=0.95)$, number of $2 \mathrm{PN}(\mathrm{P}=0.45)$, number of available embryos $(\mathrm{P}=0.74)$, stage of embryo transfer $(\mathrm{P}=0.57)$, number of embryos transferred $(\mathrm{P}=0.97)$ and sex of the newborn $(\mathrm{P}=0.62)$ were comparable between the groups. The incidence of OHSS was higher in the $\mathrm{BMI}<24 \mathrm{~kg} / \mathrm{m}^{2}$ group than in the $\mathrm{BMI} \geq 24 \mathrm{~kg} / \mathrm{m}^{2}$ group $(6.2 \%$ vs. $3.1 \%$; $\mathrm{P}=0.001)$.

\section{Neonatal and Perinatal Outcomes}

To adjust for the influence of possible confounding factors, we conducted multiple logistic regression analysis. The factors included in the regression model included the maternal age (continuous variable), BMI (continuous variable), duration of infertility (continuous variable), type of infertility (primary/ secondary infertility), basal antral follicle count (continuous variable), fertilization method (IVF/ICSI), endometrial thickness on the trigger day (continuous variable), developmental stage of the embryo (cleavage/blastocyst) and serum AMH level $(<2.71$ (reference)/2.71-4.08/4.09-6.45/>6.45 ng/ml).

Regarding PCOS patients with a BMI $<24 \mathrm{~kg} / \mathrm{m}^{2}$, compared with the PTB rate of the AMH $<2.71 \mathrm{ng} / \mathrm{ml}$ group, those of the different groups were not significantly different (AMH 2.714.08, AOR (95\% CI) $=1.01$ (0.52-2.00), $\mathrm{P}=0.99$; $\mathrm{AMH} 4.09$ 6.45, AOR (95\% CI) $=0.93(0.45-1.91), \mathrm{P}=0.85 ; \mathrm{AMH}>6.45$, AOR $(95 \%$ CI $)=0.78(0.35-1.73), P=0.54)$. The different degrees of serum AMH elevation had no significant effect on SGA, LBW, macrophages, or LGA. The data are presented in Table 2.

Regarding PCOS patients with a BMI $\geq 24 \mathrm{~kg} / \mathrm{m}^{2}$, compared with the PTB rate of the $\mathrm{AMH}<2.71 \mathrm{ng} / \mathrm{ml}$ group, that of the $\mathrm{AMH}>6.45 \mathrm{ng} / \mathrm{ml}$ group was significantly higher $(\mathrm{OR}=2.47 ; 95 \%$ $\mathrm{CI}=1.34-4.55)$. After multiple logistic regression analysis, the risk of PTB in the AMH>6.45 ng/ml group was 2.1 times that in the $\mathrm{AMH}<2.71 \mathrm{ng} / \mathrm{ml}$ group $(\mathrm{AOR}=2.1 ; 95 \% \mathrm{CI}=1.01-4.37 ; \mathrm{P}=0.04)$. However, no statistically significant difference was found in the rate of SGA, LBW, macrosomia, or LGA among the groups of patients with different serum AMH levels. The specific data are presented in Table 3. 
TABLE 1 | Baseline and cycle characteristics among patients with PCOS.

\begin{tabular}{|c|c|c|c|}
\hline Parameter & $\mathrm{BMI}<24 \mathrm{~kg} / \mathrm{m}^{2}(\mathrm{~N}=1339)$ & $\mathrm{BMI} \geq 24 \mathrm{~kg} / \mathrm{m}^{2}$ (N = 1029) & $P$-value \\
\hline Maternal age (years) & $29.0(27.0,32.0)$ & $30.0(27.0,33.0)$ & $<0.001$ \\
\hline Paternal age (years) & $30.0(28.0,33.0)$ & $31.0(28.0,34.0)$ & $<0.001$ \\
\hline Duration of infertility (years) & $3.0(2.0,4.0)$ & $3.0(2.0,5.0)$ & $<0.001$ \\
\hline Type of infertility (\%) & & & $<0.001$ \\
\hline Primary infertility & $55.3(741 / 1339)$ & $45.2(465 / 1029)$ & \\
\hline Secondary infertility & $44.7(598 / 1339)$ & $54.8(564 / 1029)$ & \\
\hline Basal serum FSH level (IU/L) & $6.7(5.6,7.8)$ & $6.4(5.4,7.5)$ & $<0.001$ \\
\hline $\mathrm{AMH}(\mathrm{ng} / \mathrm{ml})$ & $4.1(2.7,6.4)$ & $4.0(2.7,6.6)$ & 0.95 \\
\hline Basal antral follicle count & $19(15,24)$ & $21(15,24)$ & $<0.001$ \\
\hline Dosage of gonadotropins (IU) & $1950.0(1500.0,2625.0)$ & $2562.0(1950.0,3300.0)$ & $<0.001$ \\
\hline Duration of ovarian stimulation (days) & $13(12,14)$ & $13(12,15)$ & $<0.001$ \\
\hline No. of oocytes retrieved & $15(12,19)$ & $15(11,18)$ & 0.01 \\
\hline No. of $2 \mathrm{PN}$ & $10(7,13)$ & $10(6,13)$ & 0.45 \\
\hline No. of available embryos & $8(5,11)$ & $8(5,11)$ & 0.74 \\
\hline Endometrial thickness on the trigger day (mm) & $11.0(10.0,13.0)$ & $11.7(10.0,13.0)$ & 0.01 \\
\hline OHSS rate (\%) & $6.2(83 / 1339)$ & $3.1(32 / 1029)$ & 0.001 \\
\hline Fertilization method (\%) & & & 0.045 \\
\hline IVF & $73.0(977 / 1339)$ & $76.6(788 / 1029)$ & \\
\hline ICSI & $27.0(362 / 1339)$ & $23.4(241 / 1029)$ & \\
\hline Stage of embryo transfer (\%) & & & 0.57 \\
\hline Cleavage embryo & $50.3(674 / 1339)$ & $51.5(530 / 1029)$ & \\
\hline Blastocyst & $49.7(665 / 1339)$ & $48.5(499 / 1029)$ & \\
\hline No. of embryo transfers (\%) & & & 0.97 \\
\hline 1 & $54.9(735 / 1339)$ & $54.8(564 / 1029)$ & \\
\hline 2 & $45.1(604 / 1339)$ & $45.2(465 / 1029)$ & \\
\hline Neonatal birth weight (g) & $3300.0(3050.0,3600.0)$ & $3500.0(3150.0,3800.0)$ & $<0.001$ \\
\hline Gestational weeks at delivery (weeks) & $39(38,40)$ & $39(38,40)$ & 0.01 \\
\hline Gender of newborn (\%) & & & 0.62 \\
\hline Male & $56.6(758 / 1339)$ & $55.6(572 / 1029)$ & \\
\hline Female & $43.4(581 / 1339)$ & $44.4(457 / 1029)$ & \\
\hline
\end{tabular}

The data are presented as medians (P25, P75) for continuous variables and $\%(n / N)$ for categorical variables.

\section{DISCUSSION}

Among PCOS patients with a $\mathrm{BMI}<24 \mathrm{~kg} / \mathrm{m}^{2}$, different AMH levels had no significant effect on the outcomes of singleton offspring, including PTB, SGA, LBW, macrosomia and LGA. However, among patients with a BMI $\geq 24 \mathrm{~kg} / \mathrm{m}^{2}$, serum $\mathrm{AMH}>6.45 \mathrm{ng} / \mathrm{ml}$ was an independent risk factor for PTB but not for SGA, LBW, macrosomia or LGA.

\section{Comparison With Current Studies}

Currently, regardless of whether PCOS patients achieve pregnancy naturally or through IVF, the risks of perinatal complications, including pregnancy-induced hypertension, gestational diabetes mellitus, miscarriage and PTB, may increase $(7,25)$. However, no clear indicators exist concerning the exact risk factors for adverse perinatal outcomes in the PCOS population. For a long time, the serum AMH levels have been considered an indicator of ovarian reserve, and an increase in AMH levels may suggest the existence of PCOS $(26,27)$. Additionally, the AMH level in the PCOS population is significantly higher than that in the non-PCOS population (13, $15,28)$. To our best knowledge, only three clinical studies have analyzed the relationship between the serum AMH levels and preterm birth to date. J.Y. Hsu et al. (10) performed a retrospective cohort study to investigate the association between the AMH levels and risk of adverse obstetric outcomes. Among women with PCOS, those who delivered prematurely had substantially higher AMH levels (18 vs. 6.4 $\mathrm{ng} / \mathrm{mL} ; \mathrm{P}=0.003$ ) than those who delivered at term. Additionally, all women with PCOS and AMH levels above the 90th percentile had premature deliveries. Another retrospective cohort study performed in China including 25,165 IVF cycles showed that preterm deliveries were predominant among PCOS patients with AMH levels above the 75th percentile $(9.75 \mathrm{ng} / \mathrm{mL}$ ) (adjusted $\mathrm{P}<0.0001 ; \mathrm{AOR}=4.0 ; 95 \% \mathrm{CI}=1.94-8.08)$ ) and patients with frozen-thawed embryo transfer (FET) with AMH levels higher than the 90th percentile $(10.10 \mathrm{ng} / \mathrm{mL}$ ) (adjusted $\mathrm{P}<0.05$; $\mathrm{AOR}=2.0 ; 95 \% \mathrm{CI}=1.16-3.36$ ) (9). Recently, a secondary analysis of data from two multicenter randomized clinical trials including a non-IVF PCOS population indicated that $62 \%$ of participants who delivered preterm had AMH levels above the 75 th percentile $(>9.3 \mathrm{ng} / \mathrm{ml}$ ) $(8)$. However, the article did not analyze different BMI groups, particularly overweight PCOS patients who may be more severely ill $(19,21)$. Several studies have explored the impact of the maternal BMI on the safety indicators for offspring, such as the PTB rate. A meta-analysis showed that different maternal BMIs have different effects on the incidence of PTB in offspring (29). Another Chinese cohort study showed that women who are overweight, obese, and nulliparous are at an increased risk of elective preterm birth (overweight 
TABLE 2 | Neonatal outcomes among patients with PCOS and a BMl<24 kg/m² among the groups.

\begin{tabular}{|c|c|c|c|c|}
\hline & \multicolumn{4}{|c|}{ Serum AMH level (ng/ml) } \\
\hline & $<2.71(\mathrm{~N}=333)$ & $2.71-4.08(\mathrm{~N}=330)$ & $4.09-6.45(\mathrm{~N}=351)$ & $>6.45(\mathrm{~N}=325)$ \\
\hline \multicolumn{5}{|l|}{ SGA } \\
\hline$\%(\mathrm{n} / \mathrm{N})$ & $5.4(18 / 333)$ & $4.2(14 / 330)$ & $7.1(25 / 351)$ & $6.2(20 / 325)$ \\
\hline OR $(95 \% \mathrm{Cl})$ & 1 & $0.78(0.38-1.59)$ & $1.34(0.72-2.51)$ & $1.15(0.60-2.21)$ \\
\hline Adjusted OR (95\% Cl) & 1 & $0.71(0.34-1.50)$ & $1.17(0.58-2.37)$ & $1.02(0.47-2.21)$ \\
\hline Adjusted $\mathrm{P}$ value & & 0.37 & 0.70 & 0.96 \\
\hline \multicolumn{5}{|l|}{ LBW } \\
\hline$\%(n / N)$ & $4.2(14 / 333)$ & $5.2(17 / 330)$ & $4.8(17 / 351)$ & $5.2(17 / 325)$ \\
\hline OR $(95 \% \mathrm{Cl})$ & 1 & $1.24(0.60-2.55)$ & $1.16(0.56-2.39)$ & $1.26(0.61-2.60)$ \\
\hline Adjusted OR (95\% Cl) & 1 & $1.15(0.54-2.47)$ & $0.99(0.44-2.22)$ & $0.95(0.40-2.25)$ \\
\hline Adjusted P value & - & 0.72 & 0.97 & 0.91 \\
\hline \multicolumn{5}{|l|}{ Macrosomia } \\
\hline$\%(n / N)$ & $7.2(24 / 333)$ & $8.5(28 / 330)$ & $8.3(29 / 351)$ & $9.2(30 / 325)$ \\
\hline OR $(95 \% \mathrm{Cl})$ & 1 & $1.19(0.68-2.11)$ & $1.16(0.66-2.04)$ & $1.31(0.75-2.29)$ \\
\hline Adjusted OR (95\% Cl) & 1 & 1.09 (0.60-1.98) & $1.06(0.56-1.99)$ & $1.04(0.53-2.03)$ \\
\hline Adjusted $\mathrm{P}$ value & - & 0.78 & 0.86 & 0.92 \\
\hline \multicolumn{5}{|l|}{ LGA } \\
\hline$\%(n / N)$ & $14.1(47 / 333)$ & $17.0(56 / 330)$ & $13.7(48 / 351)$ & $14.2(46 / 325)$ \\
\hline OR $(95 \% \mathrm{Cl})$ & 1 & $1.24(0.82-1.90)$ & $0.96(0.63-1.49)$ & $1.00(0.65-1.56)$ \\
\hline Adjusted OR (95\% Cl) & 1 & $1.19(0.77-1.86)$ & $0.95(0.58-1.54)$ & $0.90(0.53-1.52)$ \\
\hline Adjusted P value & - & 0.44 & 0.83 & 0.69 \\
\hline \multicolumn{5}{|l|}{ PTB } \\
\hline$\%(\mathrm{n} / \mathrm{N})$ & $5.4(18 / 333)$ & $5.8(19 / 330)$ & $6.3(22 / 351)$ & $5.8(19 / 325)$ \\
\hline OR $(95 \% \mathrm{Cl})$ & 1 & 1.07 (0.55-2.08) & $1.17(0.62-2.22)$ & $1.09(0.56-2.11)$ \\
\hline Adjusted OR (95\% Cl) & 1 & $1.00(0.52-2.00)$ & $0.93(0.45-1.91)$ & $0.78(0.35-1.73)$ \\
\hline Adjusted $\mathrm{P}$ value & - & 0.99 & 0.85 & 0.54 \\
\hline
\end{tabular}

The analyses were adjusted for the maternal age, BMI, duration of infertility, type of infertility (Primary/Secondary infertility), basal antral follicle count, fertilization method (IVF/ICSI), endometrial thickness on the trigger day and development stage of the embryo (cleavage/blastocyst). OR, odds ratio; Cl ,confidence interval; SGA ,small-for-gestational age; LBW ,low birthweight; LGA, large-for-gestational age; PTB, preterm birth.

women: $\mathrm{OR}=1.36,95 \% \mathrm{CI}: 1.18-1.56$; obese women: $\mathrm{OR}=2.94$, 95\% CI: 2.04-4.25) (30). However, in a retrospective cohort study of 1680 women with PCOS undergoing FET, women who were overweight or obese did not exhibit significant differences in the rate of PTB compared with women of normal weight (31). The influence of the mother's BMI on the PTB rate of children was also present in the PCOS population, and it was more significant in the high $\mathrm{AMH}$ group. In this study, among PCOS patients with a $\mathrm{BMI}<24 \mathrm{~kg} / \mathrm{m}^{2}$, no significant correlation was found between elevated AMH levels and PTB or neonatal outcomes. However, among PCOS patients with a BMI $>24 \mathrm{~kg} /$ $\mathrm{m}^{2}$, the PTB rate of singleton offspring was significantly increased when the AMH level was greater than the 75 th percentile $(6.45 \mathrm{ng} / \mathrm{ml})$.

\section{Possible Biological Mechanism}

Our study showed that elevated AMH levels are an independent risk factor for PTB among singletons of overweight PCOS patients, but the exact biological mechanism remains unclear. However, a direct link may exist between the AMH level and $\mathrm{PTB}$, a finding that is biologically reasonable. The serum $\mathrm{AMH}$ level of PCOS patients is higher than that of non-PCOS individuals, indicating that $\mathrm{AMH}$ is an important indicator that can be used to assist in the diagnosis of PCOS (27). This dynamic does not occur only in the nonpregnancy period; the $\mathrm{AMH}$ level of the PCOS population during pregnancy is also significantly higher than that of the non-PCOS population, and the increase in the AMH level of PCOS patients may affect the endocrine system of the fetus and offspring (28). Research on its related mechanism is concentrated mainly on animal models. $\mathrm{AMH}$ is both a gonadal hormone and a putative paracrine regulator of neurons, the uterus, and the placenta, and high $\mathrm{AMH}$ levels can lead to miscarriage phenotypes in mouse model studies (32). We speculate that this phenomenon may be comparable to PTB in humans. Current studies have shown that $\mathrm{AMH}$ type II receptors exist on the surface of the myometrium and endometrial stroma and gland cells (33-35). Additionally, several studies have confirmed that $\mathrm{AMH}$ has a significant proapoptotic effect on tissues of Müllerian duct origin (36). Therefore, high AMH levels may inhibit myometrial hyperplasia during pregnancy, leading to uterine volume limitation and an increased risk of PTB (37). Alternatively, high AMH levels in early pregnancy can directly alter decidual and/or placental formation (37), as discussed by Hsu et al. (10). We also showed the relationship between high $\mathrm{AMH}$ levels and PTB. Interestingly, this effect was more significant in overweight PCOS patients, but this relationship was not significant in nonoverweight PCOS patients. Its specific biological mechanism warrants further study.

\section{Strengths and Limitations}

To our best knowledge, only three clinical studies have analyzed the relationship between the serum AMH levels and premature delivery of singleton offspring (8-10). One concerns a non-IVF- 
TABLE 3 | Neonatal outcomes among patients with PCOS and a BMl $\geq 24 \mathrm{~kg} / \mathrm{m}^{2}$ among the groups.

\begin{tabular}{|c|c|c|c|c|}
\hline & \multicolumn{4}{|c|}{ Serum AMH level (ng/ml) } \\
\hline & $<2.71(\mathrm{~N}=255)$ & $2.71-4.08(N=267)$ & 4.09-6.45 ( $N=239)$ & $>6.45(\mathrm{~N}=268)$ \\
\hline \multicolumn{5}{|l|}{ SGA } \\
\hline$\%(n / N)$ & $3.9(10 / 255)$ & $4.1(11 / 267)$ & $4.6(11 / 239)$ & $4.9(13 / 268)$ \\
\hline OR $(95 \% \mathrm{Cl})$ & 1 & $1.05(0.44-2.52)$ & $1.18(0.49-2.84)$ & $1.25(0.54-2.90)$ \\
\hline Adjusted OR (95\% Cl) & 1 & $0.98(0.39-2.44)$ & $1.04(0.39-2.76)$ & $1.13(0.41-3.15)$ \\
\hline Adjusted $P$ value & & 0.97 & 0.94 & 0.82 \\
\hline \multicolumn{5}{|l|}{ LBW } \\
\hline$\%(n / N)$ & $5.9(15 / 255)$ & $4.1(11 / 267)$ & $4.6(11 / 239)$ & $4.1(11 / 268)$ \\
\hline OR (95\% Cl) & 1 & $0.69(0.31-1.53)$ & $0.77(0.35-1.72)$ & $0.69(0.31-1.52)$ \\
\hline Adjusted OR (95\% Cl) & 1 & $0.64(0.28-1.47)$ & $0.63(0.26-1.56)$ & $0.51(0.19-1.36)$ \\
\hline Adjusted $\mathrm{P}$ value & & 0.29 & 0.32 & 0.18 \\
\hline \multicolumn{5}{|l|}{ Macrosomia } \\
\hline$\%(n / N)$ & $14.9(38 / 255)$ & $14.6(39 / 267)$ & $13.4(32 / 239)$ & $18.7(50 / 268)$ \\
\hline OR $(95 \% \mathrm{Cl})$ & 1 & 0.98 (0.60-1.59) & $0.88(0.53-1.47)$ & $1.31(0.83-2.08)$ \\
\hline Adjusted OR (95\% Cl) & 1 & $0.89(0.53-1.47)$ & $0.71(0.40-1.25)$ & $0.99(0.56-1.74)$ \\
\hline Adjusted $\mathrm{P}$ value & & 0.63 & 0.23 & 0.96 \\
\hline \multicolumn{5}{|l|}{ LGA } \\
\hline$\%(n / N)$ & $27.1(69 / 255)$ & $25.1(67 / 267)$ & $24.3(58 / 239)$ & $32.5(87 / 268)$ \\
\hline OR $(95 \% \mathrm{Cl})$ & 1 & $0.90(0.61-1.34)$ & $0.86(0.58-1.30)$ & $1.30(0.89-1.89)$ \\
\hline Adjusted OR (95\% Cl) & 1 & $0.82(0.54-1.23)$ & 0.69 (0.43-1.08) & $0.91(0.57-1.44)$ \\
\hline Adjusted $\mathrm{P}$ value & & 0.34 & 0.11 & 0.68 \\
\hline \multicolumn{5}{|l|}{ РТВ } \\
\hline$\%(n / N)$ & $6.3(16 / 255)$ & $5.2(14 / 267)$ & $10.5(25 / 239)$ & $14.2(38 / 268)$ \\
\hline OR $(95 \% \mathrm{Cl})$ & 1 & $0.83(0.40-1.73)$ & 1.75 (0.91-3.36) & $2.47(1.34-4.55)$ \\
\hline Adjusted OR (95\% Cl) & 1 & $0.80(0.38-1.71)$ & $1.63(0.79-3.35)$ & $2.1(1.01-4.37)$ \\
\hline Adjusted P-value & & 0.56 & 0.19 & 0.04 \\
\hline
\end{tabular}

The analyses were adjusted for the maternal age, BMI, duration of infertility, type of infertility(Primary/Secondary infertility), basal antral follicle count, fertilization method(IVF/ICSI), endometrial thickness on the trigger day and development stage of embryo(cleavage/blastocyst). OR, odds ratio; Cl, confidence interval; SGA, small-for-gestational age; LBW, low birthweight; LGA, large-for-gestational age; PTB, preterm birth.

assisted PCOS population (8), and the others describe IVFassisted pregnancy populations $(9,10,21)$. This study is the first clinical study to analyze the relationship between premature delivery and serum AMH in PCOS patients with different BMIs. It provides more data support for clinical consultation and new ideas for future clinical and basic research. This study also has certain limitations that must be addressed. First, this study was a retrospective cohort study with probable confounding factors. However, the sample size of this study was large, with a total of 2368 singleton births, and the influence of confounding factors was corrected through multiple logistic regression. Second, because of a lack of data, this study did not include insulin resistance in the grouping and analysis. However, we excluded gestational diabetes and hypertension to reduce the confounding effects of pregnancy complications on premature delivery and fetal development. Additionally, because of population differences and different monitoring machines, no uniform standard exists concerning how much AMH will affect the safety of offspring, and specific analyses must be performed based on the situation of their respective reproductive centers. This study was grouped according to the quartile of the serum $\mathrm{AMH}$ value. The results of the study showed that an $\mathrm{AMH}$ concentration above the 75 th percentile $(6.45 \mathrm{ng} / \mathrm{ml})$ was an independent risk factor for singleton PTB in the overweight PCOS group. AMH is not a diagnostic indicator for PCOS patients, but high AMH is a characteristic of PCOS patients.
Whether more effective indicators can represent the characteristics of PCOS patients warrants further study. Another limitation is the diagnosis of the PCOS population. Our diagnosis was primarily based on the Rotterdam criteria established in the 2003 Rotterdam consensus workshop (1). However, this study did not specifically distinguish between different PCOS phenotypes. Different PCOS phenotypes have differences in clinical and biological characteristics. Considering the diversity and heterogeneity of the clinical characteristics of PCOS patients, future clinical studies must also further analyze more specific phenotypic characteristics.

\section{CONCLUSION}

In summary, among PCOS patients with a $\mathrm{BMI}<24 \mathrm{~kg} / \mathrm{m}^{2}$, the $\mathrm{AMH}$ level had no significant effects on singleton offspring outcomes, such as PTB, SGA, LBW, macrosomia, and LGA. However, among PCOS patients with a BMI $\geq 24 \mathrm{~kg} / \mathrm{m}^{2}$, serum $\mathrm{AMH}>6.45 \mathrm{ng} / \mathrm{ml}$ (75th percentile) is an independent risk factor for PTB but not an independent risk factor for SGA, LBW, macrosomia, or LGA. Therefore, for overweight PCOS patients with high $\mathrm{AMH}$, obstetricians and pediatricians must focus on the pregnancy and perinatal period. However, the specific high $\mathrm{AMH}$ value must also be combined with the data of the respective reproductive centers, and larger, prospective, and 
well-designed randomized controlled studies are required for further analysis and research.

\section{DATA AVAILABILITY STATEMENT}

The raw data supporting the conclusions of this article will be made available by the authors, without undue reservation.

\section{ETHICS STATEMENT}

The studies involving human participants were reviewed and approved by The Third Affiliated Hospital of Zhengzhou University. Written informed consent for participation was not required for this study in accordance with the national legislation and the institutional requirements.

\section{REFERENCES}

1. Rotterdam ESHRE/ASRM-Sponsored PCOS Consensus Workshop Group. Revised 2003 Consensus on Diagnostic Criteria and Long-Term Health Risks Related to Polycystic Ovary Syndrome. Fertil Steril (2004) 81:19-25. doi: $10.1016 /$ j.fertnstert.2003.10.004

2. Azziz R, Carmina E, Dewailly D, Diamanti-Kandarakis E, Escobar-Morreale HF, Futterweit W, et al. Positions Statement: Criteria for Defining Polycystic Ovary Syndrome as a Predominantly Hyperandrogenic Syndrome: An Androgen Excess Society Guideline. J Clin Endocrinol Metab (2006) 91:4237-45. doi: 10.1210/jc.2006-0178

3. Bozdag G, Mumusoglu S, Zengin D, Karabulut E, Yildiz BO. The Prevalence and Phenotypic Features of Polycystic Ovary Syndrome: A Systematic Review and Meta-Analysis. Hum Reprod (2016) 31:2841-55. doi: 10.1093/humrep/ dew218

4. March WA, Moore VM, Willson KJ, Phillips DI, Norman RJ, Davies MJ. The Prevalence of Polycystic Ovary Syndrome in a Community Sample Assessed Under Contrasting Diagnostic Criteria. Hum Reprod (2010) 25:544-51. doi: 10.1093/humrep/dep399

5. Li R, Zhang Q, Yang D, Li S, Lu S, Wu X, et al. Prevalence of Polycystic Ovary Syndrome in Women in China: A Large Community-Based Study. Hum Reprod (2013) 28:2562-9. doi: 10.1093/humrep/det262

6. Sirmans SM, Pate KA. Epidemiology, Diagnosis, and Management of Polycystic Ovary Syndrome. Clin Epidemiol (2013) 6:1-13. doi: 10.2147/clep.s37559

7. Sha T, Wang X, Cheng W, Yan Y. A Meta-Analysis of Pregnancy-Related Outcomes and Complications in Women With Polycystic Ovary Syndrome Undergoing IVF. Reprod Biomed Online (2019) 39:281-93. doi: 10.1016/ j.rbmo.2019.03.203

8. Kaing A, Jaswa EA, Diamond MP, Legro RS, Cedars MI, Huddleston HG. Highly Elevated Level of Antimüllerian Hormone Associated With Preterm Delivery in Polycystic Ovary Syndrome Patients Who Underwent Ovulation Induction. Fertil Steril (2021) 115:438-46. doi: 10.1016/j.fertnstert. 2020.06.015

9. Hu KL, Liu FT, Xu H, Li R, Qiao J. High Antimüllerian Hormone Levels Are Associated With Preterm Delivery in Patients With Polycystic Ovary Syndrome. Fertil Steril (2020) 113:444-52.e1. doi: 10.1016/j.fertnstert. 2019.09.039

10. Hsu JY, James KE, Bormann CL, Donahoe PK, Pépin D, Sabatini ME. Müllerian-Inhibiting Substance/Anti-Müllerian Hormone as a Predictor of Preterm Birth in Polycystic Ovary Syndrome. J Clin Endocrinol Metab (2018) 103:4187-96. doi: 10.1210/jc.2018-01320

11. Cate RL, Mattaliano RJ, Hession C, Tizard R, Farber NM, Cheung A, et al. Isolation of the Bovine and Human Genes for Müllerian Inhibiting Substance and Expression of the Human Gene in Animal Cells. Cell (1986) 45:685-98. doi: 10.1016/0092-8674(86)90783-x

\section{AUTHOR CONTRIBUTIONS}

GC designed the study. DZ and ZW selected the population to be included and excluded. DZ and ZW extracted and analyzed the data. YN reviewed the data. DZ and ZW drafted the article. All authors contributed to the article and approved the submitted version.

\section{ACKNOWLEDGMENTS}

The authors acknowledge the patients who participated in the study and thank staff members of the reproductive center of the Third Affiliated Hospital of Zhengzhou University for their expert assistance with data collection and follow-up. We also thank American Journal Experts for their professional manuscript editing service.

12. La Marca A, Sighinolfi G, Radi D, Argento C, Baraldi E, Artenisio AC, et al. Anti-Mullerian Hormone (AMH) as a Predictive Marker in Assisted Reproductive Technology (ART). Hum Reprod Update (2010) 16:113-30. doi: 10.1093/humupd/dmp036

13. Pigny P, Merlen E, Robert Y, Cortet-Rudelli C, Decanter C, Jonard S, et al. Elevated Serum Level of Anti-Mullerian Hormone in Patients With Polycystic Ovary Syndrome: Relationship to the Ovarian Follicle Excess and to the Follicular Arrest. J Clin Endocrinol Metab (2003) 88:5957-62. doi: 10.1210/ jc.2003-030727

14. Pigny P, Jonard S, Robert Y, Dewailly D. Serum Anti-Mullerian Hormone as a Surrogate for Antral Follicle Count for Definition of the Polycystic Ovary Syndrome. J Clin Endocrinol Metab (2006) 91:941-5. doi: 10.1210/jc.20052076

15. Laven JS, Mulders AG, Visser JA, Themmen AP, De Jong FH, Fauser BC. Anti-Müllerian Hormone Serum Concentrations in Normoovulatory and Anovulatory Women of Reproductive Age. J Clin Endocrinol Metab (2004) 89:318-23. doi: 10.1210/jc.2003-030932

16. Wachs DS, Coffler MS, Malcom PJ, Chang RJ. Serum Anti-Mullerian Hormone Concentrations Are Not Altered by Acute Administration of Follicle Stimulating Hormone in Polycystic Ovary Syndrome and Normal Women. J Clin Endocrinol Metab (2007) 92:1871-4. doi: 10.1210/jc.20062425

17. Wang JG, Nakhuda GS, Guarnaccia MM, Sauer MV, Lobo RA. Müllerian Inhibiting Substance and Disrupted Folliculogenesis in Polycystic Ovary Syndrome. Am J Obstet Gynecol (2007) 196:77.e1-5. doi: 10.1016/ j.ajog.2006.07.046

18. Mulders AG, Laven JS, Eijkemans MJ, de Jong FH, Themmen AP, Fauser BC. Changes in Anti-Müllerian Hormone Serum Concentrations Over Time Suggest Delayed Ovarian Ageing in Normogonadotrophic Anovulatory Infertility. Hum Reprod (2004) 19:2036-42. doi: 10.1093/humrep/deh373

19. Gupta M, Yadav R, Mahey R, Agrawal A, Upadhyay A, Malhotra N, et al. Correlation of Body Mass Index (BMI), Anti-Mullerian Hormone (AMH), and Insulin Resistance Among Different Polycystic Ovary Syndrome (PCOS) Phenotypes - A Cross-Sectional Study. Gynecol Endocrinol Off J Int Soc Gynecol Endocrinol (2019) 35:970-3. doi: 10.1080/09513590.2019. 1613640

20. Chen X, Ni R, Mo Y, Li L, Yang D. Appropriate BMI Levels for PCOS Patients in Southern China. Hum Reprod (2010) 25:1295-302. doi: 10.1093/humrep/ deq028

21. Huang X, Wang Q, Liu T, Pei T, Liu D, Zhu H, et al. Body Fat Indices as Effective Predictors of Insulin Resistance in Obese/Non-Obese Polycystic Ovary Syndrome Women in the Southwest of China. Endocrine (2019) 65:81-5. doi: 10.1007/s12020-019-01912-1

22. Zhang J, Du M, Sun L. Supraphysiological Estradiol Levels on the hCG Trigger Day Are Associated With SGA for Singletons Born From Fresh Embryo 
Transfer. J Dev Orig Health Dis (2021) 11:1-8. doi: 10.1017/ S2040174421000234

23. Zhang J, Du M, Li Z, Wang L, Hu J, Zhao B, et al. Fresh Versus Frozen Embryo Transfer for Full-Term Singleton Birth: A Retrospective Cohort Study. J Ovarian Res (2018) 11:59. doi: 10.1186/s13048-018-0432-x

24. Dai L, Deng C, Li Y, Zhu J, Mu Y, Deng Y, et al. Birth Weight Reference Percentiles for Chinese. PloS One (2014) 9:e104779. doi: 10.1371/ journal.pone.0104779

25. Palomba S, de Wilde MA, Falbo A, Koster MP, La Sala GB, Fauser BC. Pregnancy Complications in Women With Polycystic Ovary Syndrome. Hum Reprod Update (2015) 21:575-92. doi: 10.1093/humupd/dmv029

26. Fraissinet A, Robin G, Pigny P, Lefebvre T, Catteau-Jonard S, Dewailly D. Use of the Serum Anti-Müllerian Hormone Assay as a Surrogate for Polycystic Ovarian Morphology: Impact on Diagnosis and Phenotypic Classification of Polycystic Ovary Syndrome. Hum Reprod (2017) 32:1716-22. doi: 10.1093/ humrep/dex239

27. Hart R, Doherty DA, Norman RJ, Franks S, Dickinson JE, Hickey M, et al. Serum Antimullerian Hormone (AMH) Levels Are Elevated in Adolescent Girls With Polycystic Ovaries and the Polycystic Ovarian Syndrome (PCOS). Fertil Steril (2010) 94:1118-21. doi: 10.1016/j.fertnstert.2009.11.002

28. Tata B, Mimouni NEH, Barbotin AL, Malone SA, Loyens A, Pigny P, et al. Elevated Prenatal Anti-Müllerian Hormone Reprograms the Fetus and Induces Polycystic Ovary Syndrome in Adulthood. Nat Med (2018) 24:83446. doi: 10.1038/s41591-018-0035-5

29. Torloni MR, Betrán AP, Daher S, Widmer M, Dolan SM, Menon R, et al. Maternal BMI and Preterm Birth: A Systematic Review of the Literature With Meta-Analysis. J Maternal-Fetal Med (2009) 22:957-70. doi: 10.3109/ 14767050903042561

30. Wang T, Zhang J, Lu X, Wei X, Zhu L. Maternal Early Pregnancy Body Mass Index and Risk of Preterm Birth. Arch Gynecol Obstet (2011) 284:813-9. doi: 10.1007/s00404-010-1740-6

31. Lin J, Huang J, Wang N, Kuang Y, Cai R. Effects of Pre-Pregnancy Body Mass Index on Pregnancy and Perinatal Outcomes in Women with PCOS Undergoing Frozen Embryo Transfer. BMC Pregnancy Childbirth (2019) 19 (1):487. doi: 10.1186/s12884-019-2611-1

32. McLennan IS, Koishi K, Batchelor NJ, Pankhurst MW. Mice With Either Diminished or Elevated Levels of Anti-Müllerian Hormone Have Decreased Litter Sizes. Biol Reprod (2018) 98:54-62. doi: 10.1093/biolre/iox151
33. Wang J, Dicken C, Lustbader JW, Tortoriello DV. Evidence for a MüllerianInhibiting Substance Autocrine/Paracrine System in Adult Human Endometrium. Fertil Steril (2009) 91:1195-203. doi: 10.1016/ j.fertnstert.2008.01.028

34. Kim SM, Kim YO, Lee MK, Chung YJ, Jeung IC, Kim MR, et al. Müllerian Inhibiting Substance/Anti-Müllerian Hormone Type II Receptor Protein and mRNA Expression in the Healthy and Cancerous Endometria. Oncol Lett (2019) 17:532-8. doi: 10.3892/ol.2018.9565

35. Arango NA, Kobayashi A, Wang Y, Jamin SP, Lee HH, Orvis GD, et al. A Mesenchymal Perspective of Müllerian Duct Differentiation and Regression in Amhr2-lacZ Mice. Mol Reprod Dev (2008) 75:1154-62. doi: 10.1002/ mrd.20858

36. Kim SY, Moon HM, Lee MK, Chung YJ, Song JY, Cho HH, et al. The Expression of Müllerian Inhibiting Substance/Anti-Müllerian Hormone Type II Receptor in Myoma and Adenomyosis. Obstet Gynecol Sci (2018) 61 (1):127-34. doi: 10.5468/ogs.2018.61.1.127

37. Shynlova O, Tsui P, Jaffer S, Lye SJ. Integration of Endocrine and Mechanical Signals in the Regulation of Myometrial Functions During Pregnancy and Labour. Eur J Obstet Gynecol Reprod Biol (2009) 144(Suppl 1):S2-10. doi: 10.1016/j.ejogrb.2009.02.044

Conflict of Interest: The authors declare that the research was conducted in the absence of any commercial or financial relationships that could be construed as a potential conflict of interest.

Publisher's Note: All claims expressed in this article are solely those of the authors and do not necessarily represent those of their affiliated organizations, or those of the publisher, the editors and the reviewers. Any product that may be evaluated in this article, or claim that may be made by its manufacturer, is not guaranteed or endorsed by the publisher.

Copyright $\odot 2021 \mathrm{Du}$, Zhang, Yu and Guan. This is an open-access article distributed under the terms of the Creative Commons Attribution License (CC BY). The use, distribution or reproduction in other forums is permitted, provided the original author(s) and the copyright owner(s) are credited and that the original publication in this journal is cited, in accordance with accepted academic practice. No use, distribution or reproduction is permitted which does not comply with these terms. 